\title{
A Glimpse into Plants of Medog, Tibet
}

\author{
Jipei Yue $^{1 *}$, Zhuo Zhou ${ }^{1}$, Hongliang Chen ${ }^{1,2}$ \\ ${ }^{1}$ Key Laboratory for Plant Diversity and Biogeography of East Asia, Kunming Institute of Botany, \\ Chinese Academy of Sciences, Heilongtan, Kunming, Yunnan, People's Republic of China. \\ ${ }^{2}$ University of Chinese Academy of Sciences, Beijing, China
}

\begin{abstract}
Medog is well known as the last county with available public transportation in China. Although it has very lush vegetation, our knowledge on plants of Medog is very limited because the poor transportation condition impeded comprehensive botanical survey in this area. Here we gave a brief summary of the study history on flora of Medog, and then introduced some plants with special scientific virtue, which had been collected during our recent trip to Medog.
\end{abstract}

Keywords: Medog, China, Plant, Flora

With about eighty percent of land covered by forest, Medog is among the greenest places in the world. The lush vegetation of this area is mainly attributed to its geological position, located in the east edge of Himalayan range, where the southeastward flowing Yarlung Tsangpo River changes its direction and bends northwest and then flushes down to India plain. Intensive cutting effect of the river resulted in the world's largest and deepest canyon, Yarlung Tsangpo Grand Canyon [1]. The gorge acts as moisture passage through which the Southwestern Monsoon brings wet and hot air from the Indian Ocean [2]. This area therefore is characterized by hot climate and heavy precipitation, which in turn facilitate the development of tropic to subtropical vegetation.

Another important factor contributes to its good vegetation can be attributed to its poor transportation condition. Before the year 2013 when the Galongla tunnel was built, the public transportation was not available in winter, because the pass of road at high elevation is always covered by very thick snow. However, even vehicles can use tunnel and break through snow obstacle in winter nowadays, the road can be occasionally flushed away by flood caused by heavy rain in summer. Just because of poor transportation condition, the vegetation of Medog is free of logging threaten; the main reason caused most forest loss in other parts of China in 70 s to 80 s of last century.

The suitable climate and isolated position of this area produced dense forest. On the other hand, our knowledge about the flora of Medog is very limited. The poor road condition hindered comprehensive botanical expedition on this area. So far, only few botanical collections had been conducted. The first one was carried out in 1974 by an expedition team organized by the Committee of the "Comprehensive Scientific Expedition to the Qinghai-Xizang Plateau of the Chinese Academy". The team members explored several parts of Medog and collected about 3000 sheets of specimen, which resulted in the first plant checklist known to this area. Later, some botanists made sporadic complementary collections. To further understand floristic characteristic of Medog, Prof. Wu Zhengyi, previous Academician and director of Kunming Institute of Botany (KIB), set up a subsidiary project 
"The floristic study of Yalu Tsangpo Big Bend Gorge" from the key project "Floristic Studies of Chinese Flowering Plants", which was financially supported by the Natural Science Foundation of China (NSFC). Drs. Hang Sun, Zhekun Zhou and Mr. Honyuan Yu from KIB made up of "Expedition to Medog" (ETM) Team and conducted field work to fulfill the project. From Sep. 1992 to June 1993, they spent nine months and travelled most parts of Medog, and collected 7,100 numbers and 30,000 sheets of specimen. Besides, they collected about 700 living plant materials for cytological and anatomic studies. Based on results of their studies, Hang Sun and Zhekun Zhou wrote a book [3] entitled as "Seed plants of the big bend gorge of Yalutsangpo in SE Tibet, E Himalayas", as well as published series of papers dealing with vegetation and floristic elements analyses [4] [5] [6]. These results represent so far the most comprehensive knowledge about plants of Medog.

In 2015, Prof. Hang Sun successfully applied a key project "The Complexity of the Floristic elements and its Evolutionary Mechanisms of Sino-Himalayas" from the NSFC. Compared to previous projects, this one put more emphasis on using molecular data to infer phylogeny and phytogeography of interested taxa, with the aim to clarify the original and evolution of the flora in the Sino-Himalayas. To collect study materials, three of us, Jipei Yue, Zhuo Zhou and Hongliang Chen, carried out a botanical expedition to Medog in middle of June 2016 (Figure 1). During our five days of field work, we had collected 140 numbers of specimens, some of which are specific and only occurred to Medog, and some have special scientific virtue. Here we give a brief introduction on some interesting plants collected from our trip:

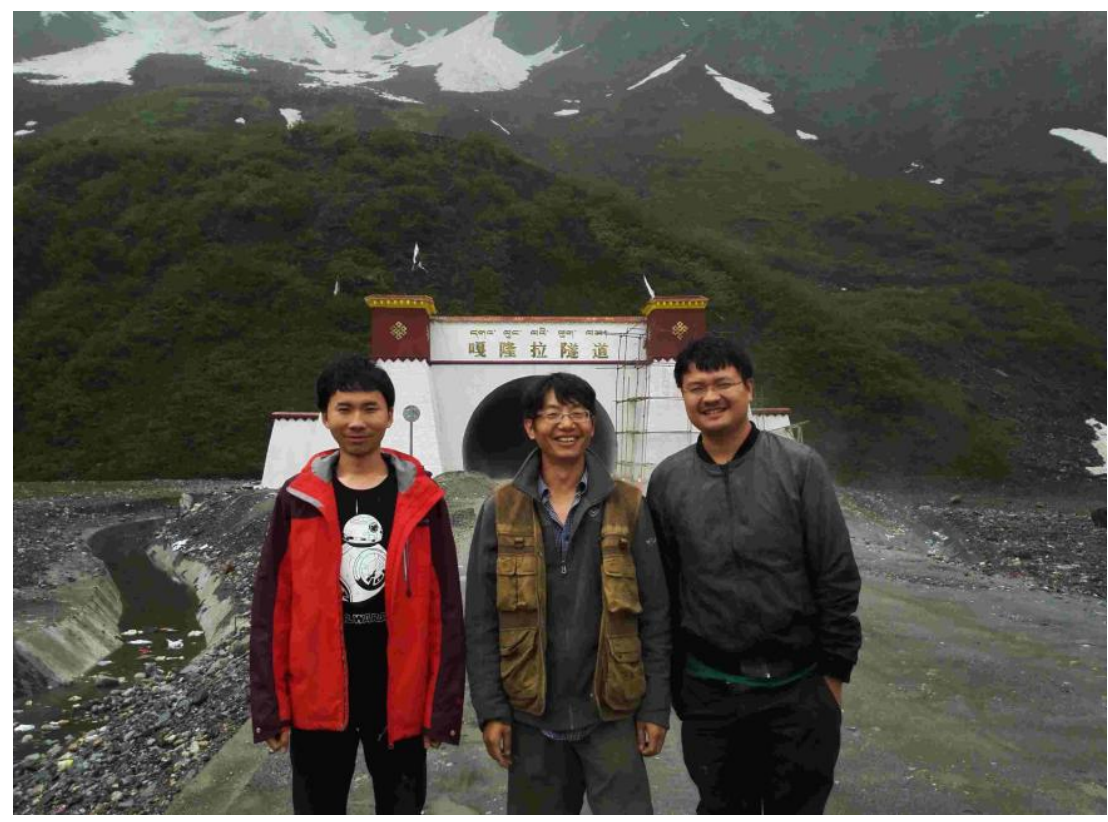

Figure1. the botanical expedition team, from left to right, Hongliang Chen, Jipei Yue, Zhuo Zhou; behind is Galongla tunnel, the gate to Medog.

\section{Beesia deltophylla C. Y. Wu}

B. deltophylla (Figure 2) is the second species in the genus Beesia (Ranunculaceae) and only occurs to Medog. The other species, B. calthifolia has wider distribution range and can be found in most provinces in Southwestern China as well as in Northern Myanmar. Both species have white sepals while no petals and they can be differentiated mainly by leaf shape and margin teeth. B. deltophylla was firstly reported in Fl. Reipubl. Popul. Sin. 27, 1979, a specimen collected by Qinhai-Xizang Team with number 3975 was designated as the type. Because of its limited distribution, there are few specimens deposited in herbarium. 
On the country, there are much more collections on B. calthifolia. This species has been sampled in cytological [7] and several molecular studies [8] [9] [10]. However, studies on B. deltophylla are very rare. So far there is only one dealing with its karyomorphology [11], and no molecular study has been conducted. With dry leave material we had collected, we will carry out relevant studies to test the monophyly of the genus Beesia and to infer the divergence time of its two species.

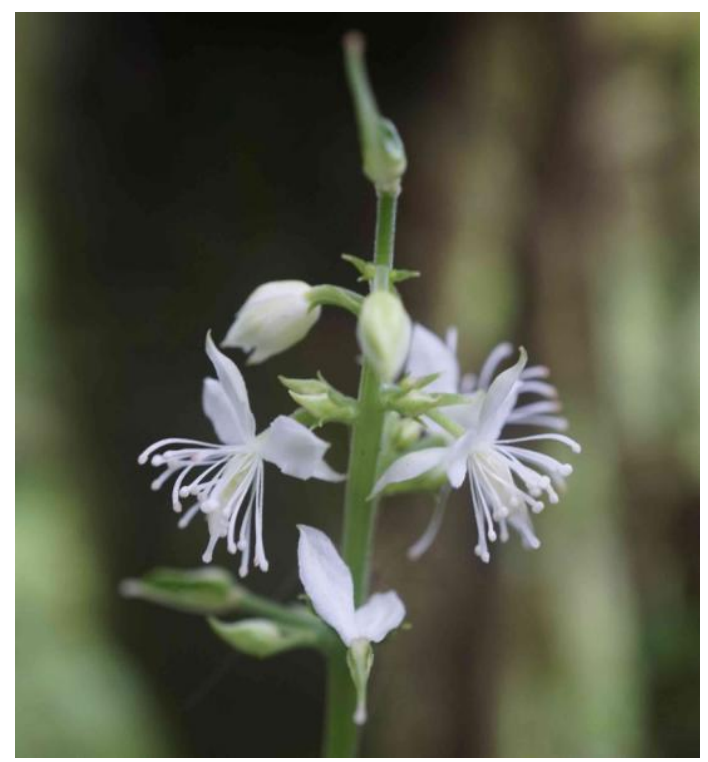

(a)

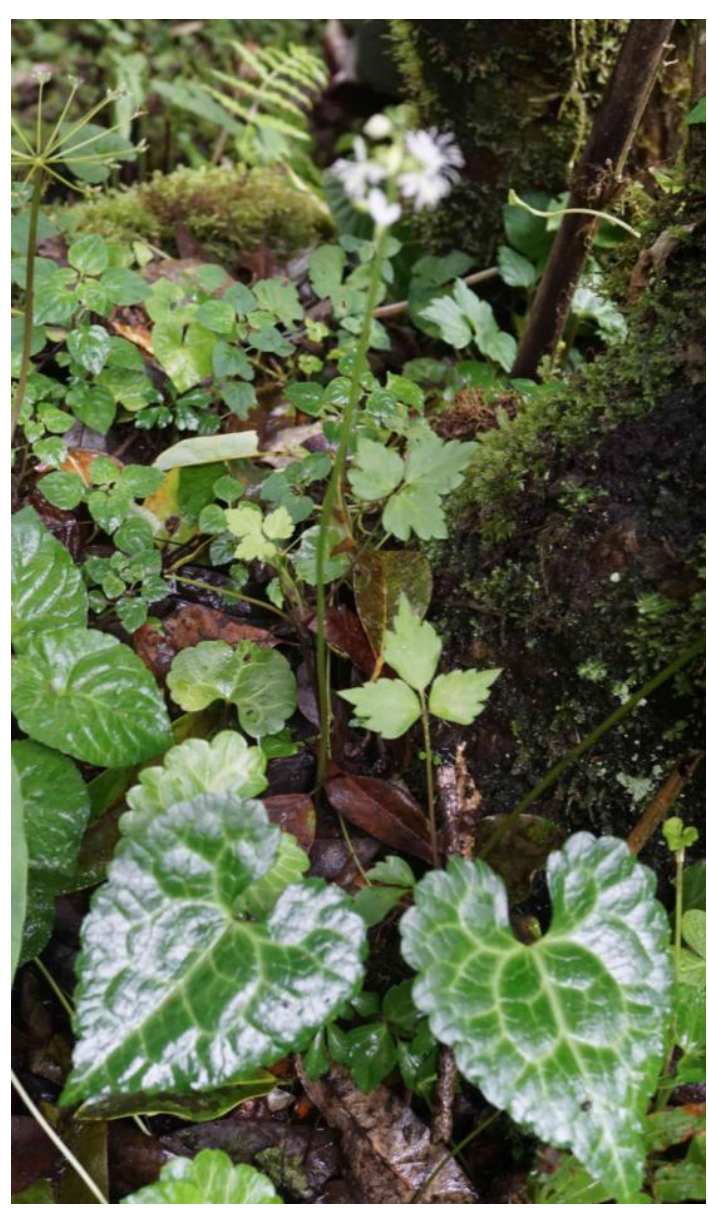

(b)

Figure2. Beesia deltophylla C.Y. Wu. (a), Raceme with apetalous white flowers; (b), plant with deltoid leaves.

\section{Pleiosorbus megacarpus L.H.Zhou \& C.Y.Wu}

P. megacarpus (Figure 3) is the type species of the monotypic genus Pleiosorbus described by Zhou $\& \mathrm{Wu}$ [12]. The authors thought that it is morphologically similar to Sorbus sect. Micromeles, Docynia and Chaenomeles in Maloideae of Rosaceae, while differs in leave margin and numbers of stamens, ovary and ovules in per locule. However, $\mathrm{Lu} \& \mathrm{Ku}$ [13] indicated that after they made critical examinations on the type specimen of $P$. megacarpus, they concluded that differentiation between Pleiosorbus and Sobus can not be held, and they proposed to unite Pleiosorbus with Sorbus and adopt a new name $S$. medogensis to replace P. megacarpus. In the following step we will use molecular data to verify weather Pleiosorbus should be reduced to synonym of Sorbus or kept as a separate genus.

Another concern should be took into consideration is its conversation status. Though it has been recorded from several places twenty years ago, we only found one individual plant in very unhealthy condition in Renqinpeng. The tree is dying and only several branches sprouted out from low base. The location of this plant is near Renqinpeng Temple, and a concrete trail for tourist is under construction nearby. Therefore, the survival expectation for this individual tree is very low and some measures should be taken as soon to protect this species from extinction. 


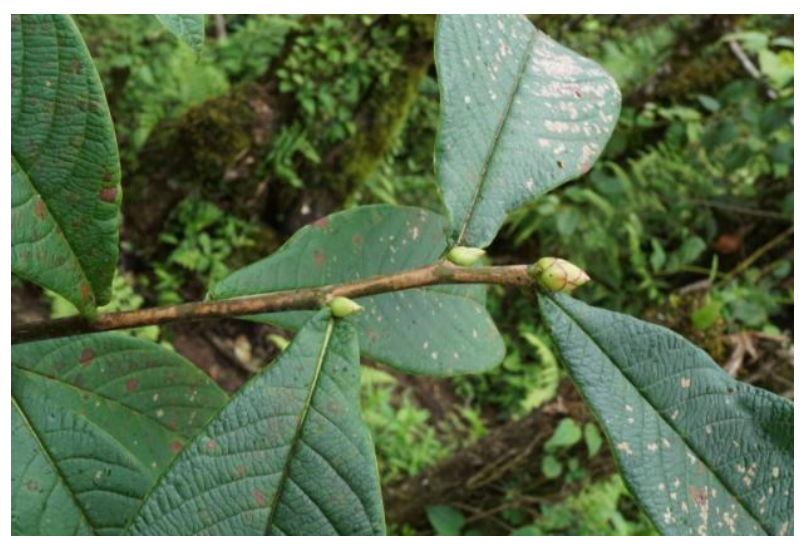

(a)

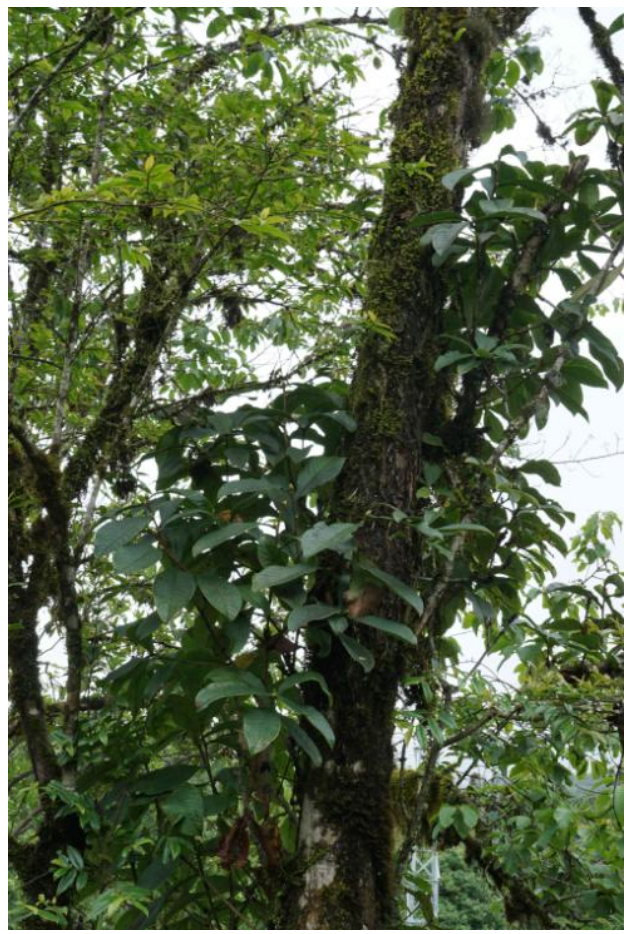

(b)

Figure3. Pleiosorbus megacarpus L.H.Zhou \& C.Y.Wu (Rosaceae), (a), twig with scaled buds and alternate leaves; (b), branches sprouted out from tree base.

\section{Helwingia himalaica Hook. f. et Thoms. ex C. B. Clarke}

H. himalaica (Figure 4) belongs to the genus Helwingia Willd., which is the only genus of the monotypic and East Asian endemic family Helwingiaceae. While another treatment put Helwingia in the family Cornoraceae [14].

Helwingia is unique by its flowers and fruits sessile and usually growing on midvein of leaf blade, rarely on petiole of leaves on upper part of young branches. The genus contains four species, i.e. $H$. japonica, H. chinensis, $H$. omeiensis and $H$. himalaica [15]. All other three species have been included in numerous molecular studies whereas there is none piece of molecular data from $H$. himalaica. We will sequence some fragments of this species to infer its relationship with other species.

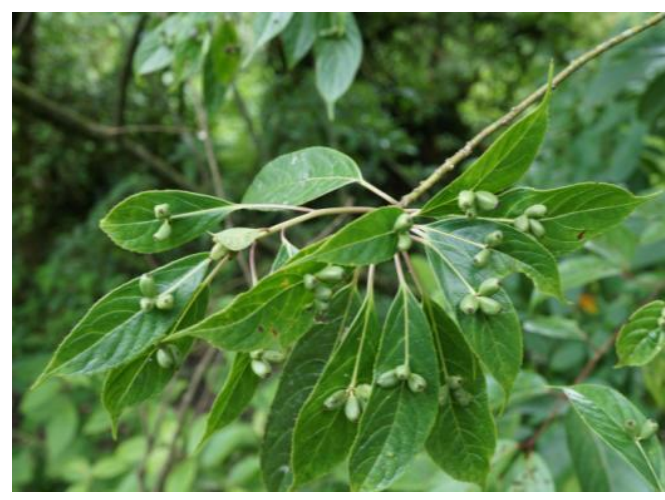

(a)

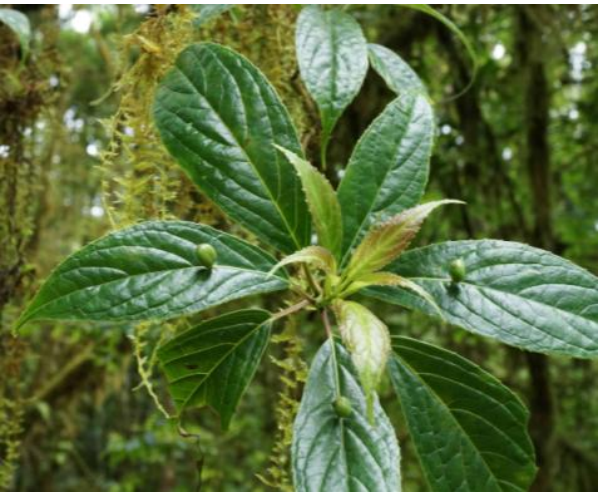

(b)

Figure4. Helwingia himalaica Hook. f. et Thoms. ex C. B. Clarke, (a), an individual plant with two to three fruits on one leaf; (b), an individual plant with only one fruit on one leaf 


\section{Galeola lindleyana (Hook. f. \& Thoms.) Rchb.f.}

G. lindleyana (Figure 5) is a peculiar Orchid. Different from general perennial herbs, this species is mycotrophic with no leaves. Stem erect, reddish brown, 1-3 m tall; panicle composed of terminal and lateral racemes. Therefore this species shows in sub-shrub morphology. This species can be found in sparse forests at 700 to 3000 meters elevation and its distribution range is from southwestern China to Bhutan, India, Indonesia and Nepal [16].

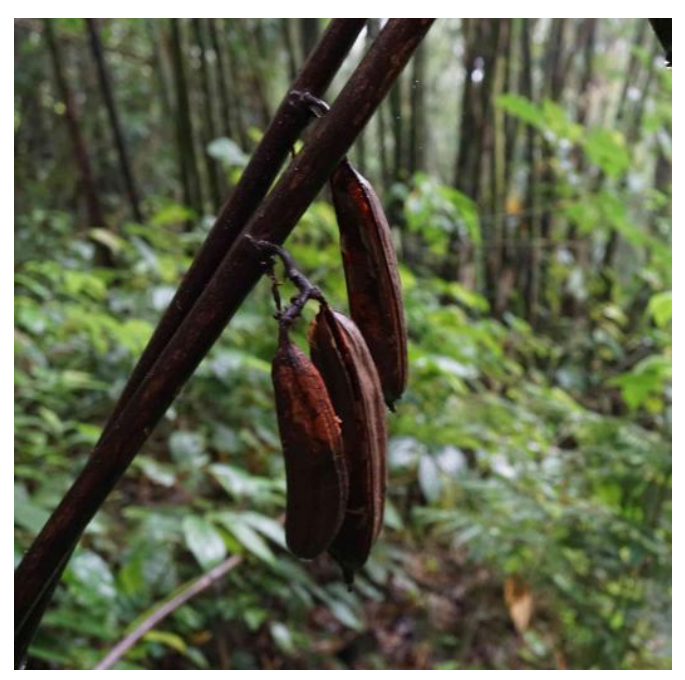

(a)

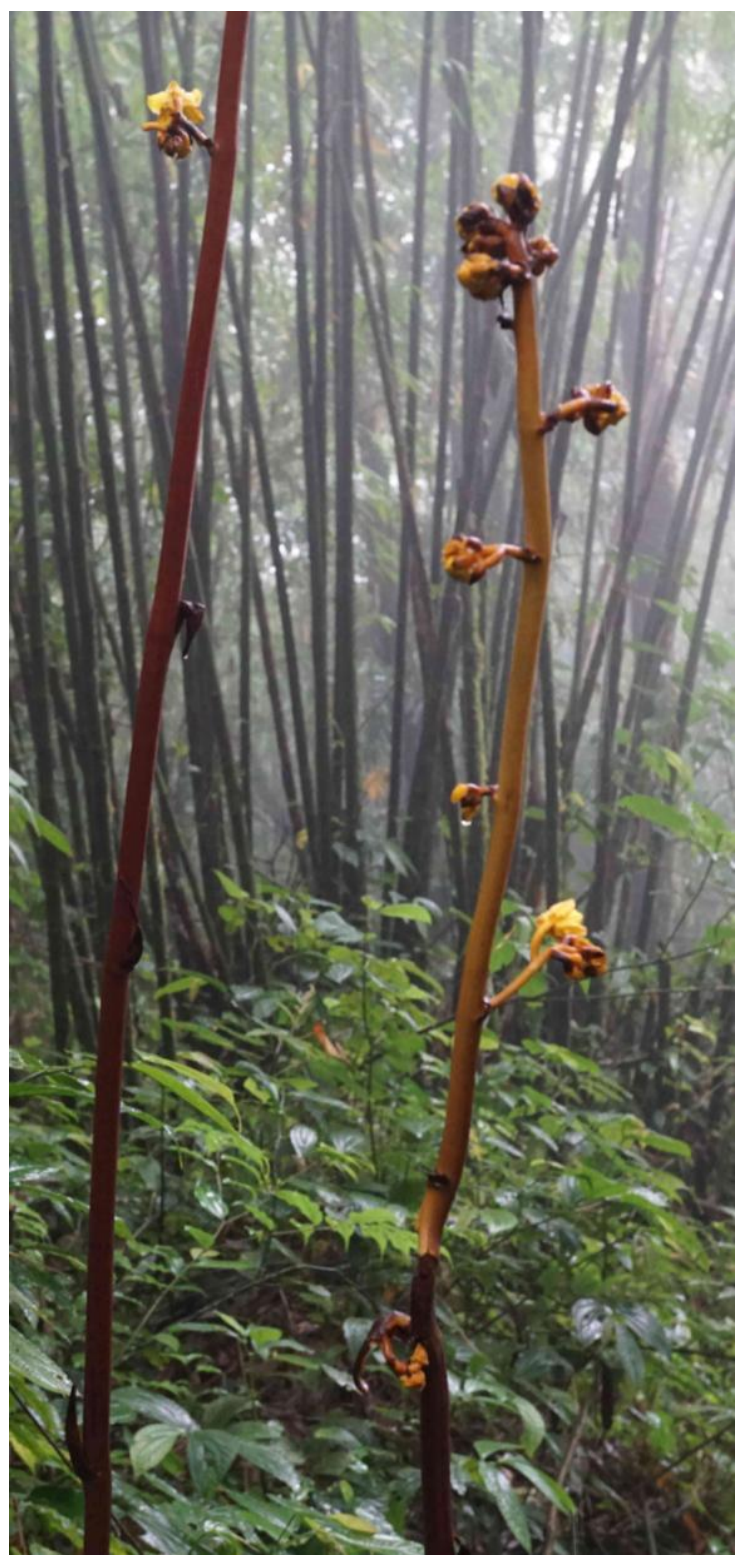

(b)

Figure5. Galeola lindleyana (Hook. f. et Thoms.) Rchb.f. (Orchidaceae). (a), dry fruits left on stem; (b), panicle inflorescence.

\section{Styrax serrulatus Roxb.}

S. serrulatus (Figure 6) belongs to Styras (Styracaceae), a New World tropic to subtropic genus with about 130 species, 31 of which occur in China [17]. Species of S. serrulatus are trees in 4-12 meters height. Compared to other congeneric species, S. serrulatus has ellipsoid to ellipsoid-ovoid fruits with acute or apiculate fruit apex and ovate, oblong, or ovate-lanceolate leaf blade with serrate or rarely entire margin. 
One unique phenomenon for S. serrulatus is that besides normal fruits, there are some special structures in Illicium fruit shape growing on the tip of twigs. This caused an illusion that there are two kinds of fruits in this species. In fact, the structures in Illicium fruit shape are insect galls. They transformed from young buds which had been infected by a kind of aphid, Ceratovacuna nekoashi. With the chemical stimulus secreted by the insect, young buds grow abnormally and finally turn into Illicium fruit shape. Knowing this situation will help to identify Styrax species quickly.

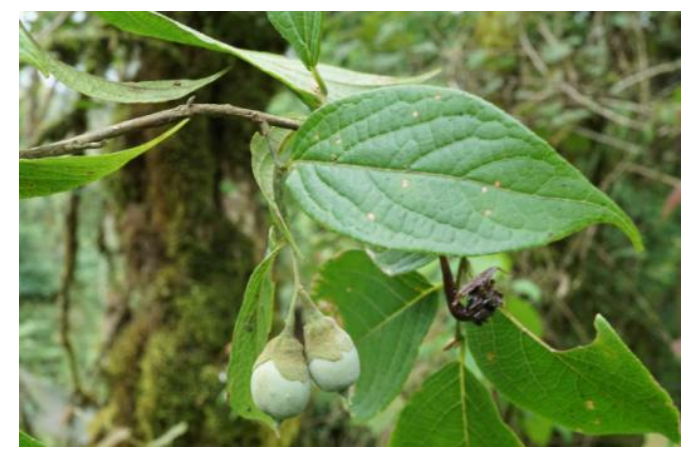

(a)

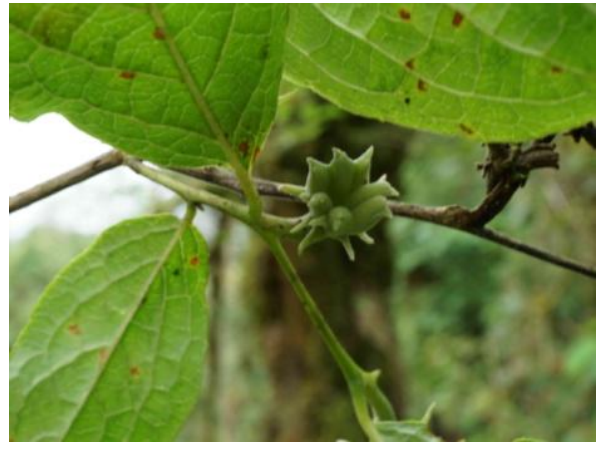

(b)

Figure6. Styrax serrulatus Roxb. (a), normal fuits; (b), insect galls in Illicium fruit shape

\section{ACKNOWLEDGEMENTS}

We thank Mr. Jianchu Deng for driving us to Medog. Fieldwork was supported by the National Natural Science Foundation of China (31170181), the Major Program of NSFC 31590820 and 31590823.

\section{REFERENCES}

[1] Yang, Y. C., Gao, D. Y. and Li. B. S. (2009) A Greatly Geographic Discovery in a Century: The Great Yalu Zangbu canyon. Chinese Journal of Nature, 31(6), 348-354.

[2] Gao, D. Y. (2008) Expeditionary studies on the moisture passage of the Yarlung Zangbo River. Chinese Journal of Nature, 30(05), 301-303.

[3] Sun, H. and Zhou, Z. K. (2002) Seed Plants of The Big Bend Gorge of Yalu Tsangpo in SE Tibet, E Himalayas. Yunnan Science \& Technology Press, Kunming

[4] Sun, H. and Zhou, Z. K. (1996) The characters and origin of the flora from the big bend gorge of Yalu Tsangpu (Brahmabutra) river, Eastern Himalayas. Acta Botanica Yunnanica, 18(2), 185-204.

[5] Sun, H. Zhou, Z. K. and Yu, H. Y. (1996) A Preliminary Probe into the Secondary Succession Series of Tropical Forests in the Big Bend Gorge of Yalu Tsangpo River in S. E. Tibet, E. Himalayas. Acta Botanica Yunnanica 18(3), 308-316.

[6] Sun, H. and Zhou, Z. K. (1997) The Phytogeoraphical affinities and nature of the big bend gorge of the Yalu Tsangpo river, S.E. Tibet, E. Himalayas China. Chinese Journal of Applied and Environmental Biology, 3(2), 184-190.

[7] Shang, X. M. (1985) Chromosome Studies of Subgenus Gymnaconitum Endemic to China and Beesia (Ranunculaceae). Journal of University of Chinese Academy of Sciences, 23(4), 270-274.

[8] Wang, X. (1998) The systematic position of Beesia: evidence from its (nrdna) sequence analysis. Acta Phytotaxonomica Sinica, 36, 403-410.

[9] Wang, W. Li, R. Q. and Chen, Z. D. (2005) Systematic position of asteropyrum, (ranunculaceae) inferred from chloroplast and nuclear sequences. Plant Systematics \& Evolution, 255(1-2), 41-54. 
[10] Wang, W. and Chen, Z. D. (2010) Phylogenetic placements of calathodes and megaleranthis (ranunculaceae): evidence from molecular and morphological data. Taxon, 59(6), 1712-1720.

[11] Yang, Q. E., Gu, Z. J. and Sun, H. (1995) The karyotype of Beesia deltophylla and its systematic significance. Acta Phytotaxonomica Sinica, 32(3), 225-229.

[12] Zhou, L. H. and\& Wu, Z. Y. (2000) Pleiosorbus, a new genus of rosaceae from Xizang (tibet), china. Acta Botanica Yunnanica, 22(4), 383-389.

[13] Lu, L. and Ku, T. C. (2002) Pleiosorbus is united with sorbus (rosaceae). Acta Phytotaxonomica Sinica, 40, 475-476.

[14] Cronquist, S. (1981) An integrated system of classification of flowering plants. Columbia University Press, New York.

[15] Xian, Q. Y. and Boufford, D. E. (2005) Helwingiaceae. In: Wu, Z.Y. \& Raven, P. H. (Eds.) Flora of China 14. Science Press and Missouri Botanical Garden Press, Beijing and St. Louis, 227-229.

[16] Chen, X. Q. and Cribb, P. J. (2009) Galeola. In: Wu, Z.Y. \& Raven, P. H. (Eds.) Flora of China 25. Science Press and Missouri Botanical Garden Press, Beijing and St. Louis, 169-170.

[17] Huang, S. M. and Grimes, J. W. (1996) Styrax. In: Wu, Z.Y. \& Raven, P. H. (Eds.) Flora of China 15. Science Press and Missouri Botanical Garden Press, Beijing and St. Louis, 253-263. 